\title{
Traditional Food and Health Practices during Post-Partum Period: A Study among Tribal Women of Fakir Gujri, District Srinagar, Jammu and Kashmir
}

\author{
Bhinish Shakeel $^{1 *}$, Hummara Azim² and Nayeema Jabeen ${ }^{2}$ \\ ${ }^{1}$ Home Science Extension Education, Krishi Vigyan Kendra - Srinagar Shere Kashmir \\ University of Agricultural Sciences and Technology (SKUAST-K) Kashmir, India \\ ${ }^{2}$ Institute of Home Science, University of Kashmir, Hazratbal, $J \& K$, India \\ ${ }^{3}$ Department of Olericulture, Shere Kashmir University of Agricultural Sciences and \\ Technology (SKUAST-K), India \\ *Corresponding author
}

\section{A B S T R A C T}

\begin{tabular}{|l|}
\hline Ke y w o r d s \\
Indigenous \\
Knowledge, \\
Pregnancy and \\
Lactation, Post- \\
Partum, Lossa \\
Ghasse, Jammu and \\
Kashmir \\
\hline Article Info \\
\hline $\begin{array}{l}\text { Accepted: } \\
\text { 08 July 2018 } \\
\text { Available Online: } \\
\text { 10 August } 2018\end{array}$ \\
\hline
\end{tabular}

Ever since man came into being he has been using certain basic techniques for survival with respect to health, hygiene, food, clothing, shelter, agriculture and allied activities. These traditional methods or techniques are called as Indigenous Traditional Knowledge (ITK) of a particular community and present a wide range of information in various aspects of life. Over the last two decades a lot of information has been generated globally with respect to ITK in all walks of life. The current paper deals with traditional food and health practices during post-partum period - a critical women health issue. The study was undertaken in three blocks of the District using semi-structured interview schedule and Group Discussion. It details the ITK in pregnancy and lactation that are currently practiced by women of Fakir Gujri, a tribal area in District Srinagar, the summer capital of the State of Jammu and Kashmir. The study was conducted using semi-structured interview schedule and Group Discussion. The current paper details out the simple at-home herbal measures that are put to use by the tribal women folk to treat the discomforts of pregnancy, aid healing and bring about therapeutic effects to the body. The chapter highlights the ageold practice of the ceremonial bath taken after the baby is delivered. The water used for bathing is a decoction of herbal plants called "Losse Ghasse" that are believed to have therapeutic properties. Living in times that are a digital era influenced strongly by the advances of science and technology, there was $100 \%$ reportage of practicing these ITK by the tribal women of Fakir Gujri.

\section{Introduction}

Among the various stages of development in the lives of females, pregnancy and lactation is probably the most vulnerable stage. It marks motherhood as a demanding and challenging task not only for the baby, but for her own self as well. It is a critical period with unique nutritional demands of the foetus to be met for optimal physical and cognitive development. Therefore it calls for extra care in terms of health and food practices during 
this phase. Childbirth an important event in the life of a female is a period of transition and social celebration in many cultures, signalling an adjustment of cultural responsibilities (1). In most non-Western cultures, women receive special attention and care during this period. In any community, childbirth is a critical period of life and response towards childbirth varies from culture to culture (2). Infact, the World Health Organisation, 2006 acknowledges this as traditional practice followed by many cultures where a 40 day period of extra support is rendered to the new mother and the baby.

\section{About Fakir Gujri}

Fakir Gujri is situated in the district of Srinagar, the summer capital of the state of Jammu and Kashmir in the Zabarwan range of mountains. With a total area of 130 hectares, it has a total population of 1600 with 950 males and 650 females accommodated in 310 households. It is $28 \mathrm{~km}$ from the District Headquarters. (3) Traditionally, medicinal and aromatic plants have been used both for consumption and therapeutic use in Kashmir for many years. The nursing women are traditionally asked to follow a particular lifestyle and dietary regime which is a lot different from the diet and lifestyle they maintain before and after post-partum period as in China (4). Post-Partum Phase in a Kashmiri society is characterised strongly by the traditional food and health practices that are collectively known as "Losse-Toan" where the word "Losse" means Nursing woman and "Toan" means "Care." While on one hand the development indices exhibit a growing trend in the number of institutional deliveries among women, our findings of the study on traditional food and health practices followed in the post-partum phase suggest that people adhere strictly to the traditional food and health practices. The period of postpartum is marked by the following practices in the study area:

1. Confinement

2. Diet Regime or Diet Therapy

3. Ceremonial Therapeutic Bath

\section{A. Confinement}

The period of nursing is marked by confinement of mother and the baby. This has also been reported in many other communities in Asia which is done for enhanced care and prevention of infections to the duo.(5). This confinement is rather a set of practices to assist women recover from pregnancy and childbirth. Some of these practices may include prolonged rest $(6)$, a special diet $(7,8)$ and actions to heighten personal hygiene. Confinement practices have been linked to later maternal health conditions such as postpartum depression $(9,10)$. The significance of this 40 plus days restrictions period after the childbirth is considered as resting period which sometimes lasts for 60 days aswell. The period is characterised by strong social support for the mother usually provided by female relatives and midwives that severely restrict her activities catering to her needs as in other non-western cultures. (11). Emphasis is also laid on keeping the mother and the baby warm.

During this phase women are advised to wear loose, long body covering clothes that would keep them warm. Both mother and the baby are well clad. Use of socks is mandatory and a cap or a hear gear to keep the head warm as well. The nursing mother is strictly forbidden to use cold water for cleaning or drinking. The baby is well layered in woollen clothes and cap at all times regardless of the season. These are usually knitted by relatives and friends in order to avoid allergies in the new born and ensure comfort and warmth. If the woman delivers in winter months, the heating arrangements are well thought of in advance. 
Thin blankets are also used as window and door curtains to keep out the chill.

\section{Diet}

Special attention is paid to diet of women in post-partum phases. It is of critical importance because her diet has direct bearing on her own health and indirectly the baby. There is a common belief in the region that the diet of a woman during this phase determines the quality of milk produced. The "hotness" and "coldness" of foods determines the choice of foods to be included in per day menu. It is almost a universal practice to avoid cold foods like fresh fruits and vegetables, cold foods and plain water (12). Cold foods like curd and juices are strictly not taken as it is believed to cause respiratory ailments like cough and cold to the mother as well as the baby. After delivering the baby, a woman is fed light diet of nun chai or the Kashmiri pink salt tea with biscuits. After two days, when the appetite is restored emphasis is laid on a balanced diet, with inclusion of milk, meat, poultry, eggs, vegetables, fruit, as the top priority. Milk replaces the morning tea as caffeine intake is restricted. Mutton soup with roti or rice is fed at meal times. Seasonal fruits and vegetables are included in diet. Hund (Taraxacum officianale) and Bathua (Chenopodium album) are a weed herb which are profusely fed to the nursing woman. It is believed to have therapeutic properties that strengthens back and builds up haem in blood. Lean goat meat and fish meet the protein requirement. Broiler chicken is usually not the first choice when it comes to making broth for it is considered 'garam or hot' in essence. Intake of salt, sugar, spices, and condiments is kept minimal as these are believed to be 'garam' or hot. Pulses and cheese are strictly avoided during the early post-partum as they are believed to be 'hard to digest' foods and would interfere with normal digestion. Most importantly, methi seed and desi chawal are cooked in desi ghee to enhance breast milk supply in the nursing mother.

The above diet plan is strictly followed for the first forty days. Gradually, as the mother recuperates normal meals are added into the diet in order to restore normalcy and to acclimatize the nursing mother's body to regular meals. The above diet plan is a flexible schedule which is followed for as long as the mother's body is able to switch to regular meals. Some women take longer to revert to general meals while others take to them quickly.

It is evident from the findings that traditional food practices followed during postpartum are nutritious and wholesome. All the food groups, namely, carbohydrates, proteins, vitamins and minerals are provided to meet the enhanced nutritional demands. There is a general belief that the woman must eat well. Eating less will render her physically weak and unfit for getting back to normal life. Care is taken to procure the choicest food item in terms of variety (pure cow milk, desi eggs, desi rice, desi ghee) and hygiene. Diet is basic and largely homemade in order to ensure hygiene. The respondents stated that "Desi" food items are arranged from relatives, friends and acquaintances who arrange for these items owing to their traditional health benefits in post-partum.

\section{Therapeutic, herbal, bath}

The period post delivery of the baby is known as post-partum period which is generally defined to begin one hour after the delivery of Placenta lasting six weeks. (13). This therapeutic bath comprising of several herbal plants practised post delivery of baby. Traditionally, it is taken on the fortieth day after delivering of the baby. This is the first bath that a nursing woman undergoes after delivering. Nearly 8-10 herbs constitute the 
herb grass heap or what is called "Losse Ghassa" in kashmiri. The word "Losse" in Kashmiri means "nursing woman" and "Ghasse" means grass. The herbs are procured from the Bohris or the Traditional Health Practitioners who run specialised shops selling herbal plants and medicines. The herbs are then boiled strongly in water in traditional copper vessels called the "Deg or the Degchi" which are a common utility in every rich or poor household of Kashmir. After boiling enough to extract a decoction of various herbs, the water is poured in buckets for the nursing woman to bathe in. Usually, the "Losse" sits in the water and foments herself with some of the grass that is deliberately left in this water. There are some common health problems faced by women during this period like tiredness/exhaustion, back-ache, pain in lower uterine region, wound and sexual problems, haemorrhoids, bowel movement, urinary incontinence, contraception, more upper respiratory tract infections than usual and mastitis, (14). Based on the responses of the respondents, this bath is believed to be extremely therapeutic that enables Losse to overcome general weakness, regain body vigour lost during ante-natal phase and delivery, prevent further illness later in life like bone or muscle ache. After the bath, the woman is tucked into a bed which is well quilted and warm. Utmost care is taken to avoid exposure to cold which can render the whole exercise of bathing useless. Therefore women are confined to bed strictly after this bath. As per the humoral medicine, pregnancy is seen as a hot state; with parturition heat being lost during delivery the woman comes into a state of excess cold, and during the postpartum period, care should be taken to restore the mother to equilibrium (15). Usually the baby is also given a bath on the fortieth day. Normally, one to two such therapeutic baths are recommended as per traditional health norms. In the current study, there was $100 \%$ reportage of this bath by women during their post-partum period. Given below is the list of herbs used for preparing the decoction:

Table.1

\begin{tabular}{|r|l|l|l|}
\hline S.No & Scientific Name & Local Name & Part used \\
\hline 1. & Adiantum venustrum & Gyav Theer & Stem and leaves \\
\hline 2. & Oreganum vulgare & Wan Babbar & Leaf and stem \\
\hline 3. & Paenia emodi & Maed Sath & Bark \\
\hline 4. & Tagetus eretus & Gul-e-Tesu & Dried Flower \\
\hline 5. & Rheum emodi & Revand & Root \\
\hline 6. & Cinnamomum tamala & Tejpatie & Leaf \\
\hline 7. & Phyllanthus Emblica & Amla & Dried fruit \\
\hline 8. & Curcuma longa & Lyedar Gandr & Root \\
\hline 9. & Thymus linearis & Ajwain & Whole plant \\
\hline
\end{tabular}

In conclusion, despite the fact that the modern times are greatly influenced by advances in science and technology, our findings revealed that the health and food practices during the vulnerable period of pregnancy and lactation are kept rather traditional. The post-partum phase encompasses period of confinement marked by a special diet therapy followed by the herbal, therapeutic bath. This period makes judicious use of local flora for consumption and therapeutic use. There is strong focus on diet which is wholesome, 
nutritious and homemade. Emphasis is laid on high protein, high calorie intake both during pregnancy and lactation. Traditional food fads of classifying foods as 'hot' and 'cold' are still in vogue. There is an indication of strong socio-cultural support for post-partum among the tribals of Fakir Gujri who render support either for knitting wool sets for babies, providing food items like desi chicken, eggs, dehydrated vegetables etc.

\section{References}

1. Steinberg, S. 1996. Childbearing research: A Trans-Cultural Review. Social Science and Medicine 4, 17651784.

2. Marshall, L.B. 1985 Infant Care and Feeding in the South Pacific. Gordon and Breach Science Publishers, New York.

3. Constituency-wise Amenity Directory, issued by District Statistics and Evaluation Office, Srinagar. Planning and Development Department, Directorate of Economics and Statistics, District Srinagar, 2015-2016,

4. Liu N., Mao L., Sun X., Liu L., Chen B. \& Ding Q 2006. Post partum practices of puerperal women and their influencing factors in three regions of Hubei, China, BMC Public Health 6, 274.

5. Kim-Godwin YS. Postpartum Beliefs and Practices Among Non-Western Cultures. MCN, The American Journal of Maternal/Child Nursing. 2003; 28(2): 748.

6. Dennis C-L, Fung $\mathrm{K}$, Grigoriadis $\mathrm{S}$, Robinson GE, Romans S, Ross L. Traditional postpartum practices and rituals: a qualitative systematic review. Women's health (London, England) 2007; 3(4): 487-502.

7. Barennes H, Simmala C, Odermatt P, Thaybouavone T, Vallee J, MartinezAussel B, et al., Postpartum traditions and nutrition practices among urban Lao women and their infants in Vientiane, Lao PDR. European journal of clinical nutrition. 2009; 63(3): 323-31.

8. Choudhry UK. Traditional practices of women from India: Pregnancy, childbirth, and newborn care. Journal of Obstetric, Gynecologic, \& Neonatal Nursing. 1997; 26(5): 533-9.

9. Grigoriadis S, Erlick Robinson G, Fung $\mathrm{K}$, Ross LE, Chee CYI, Dennis C-L, et al., Traditional postpartum practices and rituals: clinical implications. Canadian journal of psychiatry Revue canadienne de psychiatrie. 2009; 54(12): 834.

10. Bao W, Ma A, Mao L, Lai J, Xiao M, Sun G, et al., Diet and lifestyle interventions in postpartum women in China: study design and rationale of a multicenter randomized controlled trial. BMC public health. 2010; 10(1):103.

11. Kim-Godwin YS. postpartum beliefs and practices among non-western cultures. MCN, The American Journal of Maternal/Child Nursing. 2003; 28(2): 74 8.

12. Boer H. De. and Lamxay V. 2009. Plants used during pregnancy, childbirth and post-partum health care in Lao PDR: A Comparative Study of the Brou, Saey and Kry ethnic groups. Journal of Ethnobiology and Ethnomedicine.

13. Blenning C.E and Paladine H. 2005. An Approach to post-partum office visit. American Family Physician 72, 24912498

14. Piejko E. The postpartum visit - Why wait 6 weeks?: 1. Australian Family Physician. 2006; 35(9): 674.

15. Roasting M.L. 2003 Smoking and Dieting: Malay Confinement in Cross Cultural Perspective. In: The Manner Born: Birth Rites in Cross Cultural Perspective (de L Dundes), pp. 137-159. Walnut Creel, CA: Altamira Press. 


\section{How to cite this article:}

Bhinish Shakeel, Hummara Azim and Nayeema Jabeen. 2018. Traditional Food and Health Practices during Post-Partum Period: A Study among Tribal Women of Fakir Gujri, District Srinagar, Jammu and Kashmir. Int.J.Curr.Microbiol.App.Sci. 7(08): 1076-1081. doi: https://doi.org/10.20546/ijcmas.2018.708.122 